\title{
LIBERTAD RELIGIOSA Y OBJECIÓN DE CONCIENCIA INSTITUCIONAL EN COLOMBIA: UN ANÁLISIS A PARTIR DE LA SENTENCIA T-738 DE 2015
}

\author{
[Religious freedom and institutional conscience objection in Colombia: an \\ analysis from the following case T-738 of 2015]
}

\author{
ROJAS, CRISTIÁN ${ }^{1}$ \\ CONTRERAS, PEDRO
}

\begin{abstract}
Resumen
El reconocimiento de la objeción de conciencia institucional en Colombia ha generado posturas contradictorias dentro de la interpretación que hace la Corte Constitucional del derecho fundamental a la libertad de conciencia. Aunque hay una postura que es vinculante y otras que no, actualmente los distintos pronunciamientos generan confusión en funcionarios, jueces y ciudadanos. El presente trabajo realiza un análisis a partir de la postura vinculante que reconoce la libertad religiosa y de conciencia a las instituciones (T-738 de 2015), observando que es la que se debe aplicar. Se evidencia también que las demás posturas que ha sostenido la jurisprudencia, además de no ser vinculantes, están basadas en un tratamiento poco riguroso de esas libertades fundamentales.

Palabras clave: Libertad religiosa, objeción de conciencia, Corte Constitucional, personas jurídicas, vinculatoriedad
\end{abstract}

\begin{abstract}
The recognition of the institutional conscientious objection has generated contradictory positions within the interpretation that the Constitutional Court has about the fundamental right to freedom of conscience. Although there is a position that is binding and others that are not, today, the different pronouncements generate confusion in officials, judges, and citizens. This essay analyzes the binding ruling that recognizes conscience and religious freedom to institutions (T-738 de 2015), noting that is the one that should be applied. It is also observed that the other positions that the jurisprudence has supported, in addition to not being binding, are based on a little rigorous treatment of these fundamental freedoms.
\end{abstract}

Keywords: Religious freedom, conscientious objection, Constitutional Court, legal persons, binding

DOI: $10.7764 / R L D R .10 .129$

\footnotetext{
1 Profesor asistente, Universidad de La Sabana, Departamento de Ciencias Políticas, cristian.rojas@unisabana.edu.co

2 Estudiante de Derecho en proceso de grado, Pontificia Universidad Javeriana, Facultad de Ciencias Jurídicas, pedro-contreras@javeriana.edu.co
} 
Cristian Rojas \& Pedro Contreras. Libertad religiosa y objeción de conciencia institucional en Colombia: Un análisis a partir de la sentencia T-738 de 2015.

\section{INTRODUCCIÓN}

En la Constitución Política de Colombia existen dos artículos que protegen la libertad religiosa, uno en sentido positivo y otro en sentido negativo, según la famosa distinción de Isaiah Berlin ${ }^{3}$. En el artículo 19 se halla esta libertad en sentido positivo -capacidad de determinarse a sí mismo-, pues reconoce que toda persona puede profesar y difundir la propia religión: "Se garantiza la libertad de cultos. Toda persona tiene derecho a profesar libremente su religión y a difundirla en forma individual o colectiva. Todas las confesiones religiosas e iglesias son igualmente libres ante la ley" ${ }^{4}$.

El artículo 18, por su parte, se refiere a la libertad de conciencia y puede entenderse como una libertad expresada en sentido negativo -ausencia de coerción-, pues habla de que "nadie será molestado por razón de sus convicciones o creencias ni compelido a revelarlas ni obligado a actuar contra su conciencia" ${ }^{5}$.

Pero ese artículo no se refiere únicamente a la religión. Para la Corte Constitucional colombiana ${ }^{6}$, la Constitución distingue las libertades de religión y de conciencia porque busca proteger también las convicciones seculares, es decir, el artículo 18 incluye tanto las creencias religiosas como las de tipo moral, humanitario o de cualquier índole cuando están profundamente arraigadas (C-370 de 2019) ${ }^{7}$. Así se entendió desde la Asamblea Nacional

\footnotetext{
${ }^{3}$ BERLIN, Isaiah. Dos conceptos de libertad y otros escritos (Madrid). Alianza editorial, 2005. ISBN: 8420672815.

${ }^{4}$ COLOMBIA. ASAMBLEA NACIONAL CONSTITUYENTE. Artículo 19. (04, julio, 1991). Constitución Política de Colombia [en línea]. [Consultado: marzo 12 de 2020]. Disponible en:

http://www.secretariasenado.gov.co/senado/basedoc/constitucion_politica_1991.html

${ }^{5}$ Ibid., art. 18.

${ }^{6}$ COLOMBIA. CORTE CONSTITUCIONAL. T-430 de 2013.Expediente: T-3274619 (10, julio, 2013). M.P. María

Victoria Calle Correa [En línea]. [Consultado: marzo 12 de 2020]. Disponible en: https://www.corteconstitucional.gov.co/relatoria/2013/T-430-13.htm

${ }^{7}$ COLOMBIA. CORTE CONSTITUCIONAL. C.370 de 2019.Expediente: D-12372. (14, agosto, 2019). M.P. Gloria Stella Ortiz [En línea]. [Consultado: marzo 12 de 2020]. Disponible en: https://www.corteconstitucional.gov.co/relatoria/2006/c-355-06.htm
} 
Cristian Rojas \& Pedro Contreras. Libertad religiosa y objeción de conciencia institucional en Colombia: Un análisis a partir de la sentencia T-738 de 2015.

Constituyente, en cuya gaceta se explica que el tema generó intensos debates y se concluyó que "la libertad de conciencia se predica también de toda creencia e ideología"8.

Bajo esta consideración, la objeción de conciencia es para la Corte un derecho fundamental derivado de la libertad de conciencia y de la libertad religiosa, como lo reconoció en el caso de un testigo de Jehová que se negó a prestar el servicio militar obligatorio (T-430 de 2013) .

Este texto se enfoca en el ejercicio de las libertades de religión y de conciencia a través de esa figura de la objeción, que es el centro de controversias constitucionales porque supone el choque entre convicciones íntimas de las personas y alguna norma jurídica cuyo cumplimiento quiere soslayarse. En concreto, se abordará la jurisprudencia de la Corte Constitucional sobre el ejercicio de este derecho por parte de las instituciones.

Actualmente en Colombia la controversia alrededor del derecho a la libertad de conciencia de las personas jurídicas ha generado decisiones contradictorias. Por un lado, está lo que ha dicho la Corte Constitucional en sentencias de constitucionalidad, de tutela y una

\footnotetext{
${ }^{8}$ COLOMBIA. ASAMBLEA NACIONAL CONSTITUYENTE. Gaceta constitucional No 112. (3, julio, 1991) Bogotá D.E. [En línea]. [Consultado: 20 junio de 2020]. Disponible en: http://babel.banrepcultural.org/cdm/ref/collection/p17054coll26/id/3850\#: :text=El\%205\%20de\%20febrero \%20de,Colombia\%20una\%20Asamblea\%20Nacional\%20Constituyente.\&text=El\%20domingo\%207\%20de\%20j ulio,4\%20de\%20julio\%20de\%201991

${ }^{9}$ CORTE CONSTITUCIONAL. Op. Cit. T-430 de 2013
} 
Cristian Rojas \& Pedro Contreras. Libertad religiosa y objeción de conciencia institucional en Colombia: Un análisis a partir de la sentencia T-738 de 2015.

sentencia de unificación ${ }^{10}$ (C-355 de 2006 ${ }^{11}$, T-209 de 2008 ${ }^{12}$, T-388 de $2009^{13}$ y SU-096 de $\left.2018^{14}\right)$. En ellas consideró que a las personas jurídicas "no podrán nunca transmitirles caracteres éticos y morales propios y exclusivos de las personas naturales" y, por lo tanto, no hay posibilidad de que se les reconozca el derecho consagrado en el artículo 18 de la Constitución. Concretamente en la SU de 2018, dijo: "Las personas jurídicas no son titulares del derecho la objeción de conciencia y, por tanto, a las entidades de seguridad social en salud no les es permitido oponerse a la práctica de la interrupción voluntaria del embarazo." (SIC).

Sin embargo, cuando la Corte estudió un caso en el que debía decidir sobre el alcance de la autonomía escolar, consideró que el primero de los tres temas principales que debía tratar "con el propósito de responder al problema jurídico planteado" era el de "los reglamentos educativos, como expresión fundamental de la libertad de asociación y de conciencia, así como de la autonomía escolar, y su fuerza vinculante para la comunidad escolar". Por lo anterior, se puede afirmar que la siguiente cita, con respecto al tema de libertad religiosa y de conciencia, hace parte de la ratio decidendi ${ }^{15}$ de la decisión de tutela

\footnotetext{
${ }^{10}$ Las sentencias de constitucionalidad se derivan de la función de control constitucional. Por su parte, las decisiones de tutela son pronunciamientos de la Corte sobre vulneración de derechos fundamentales en algún caso concreto. Las sentencias de unificación son el resultado de varios pronunciamientos de tutela sobre una materia que la Corte busca unificar. Una diferencia importante entre las últimas dos es que (por regla general) las decisiones de tutela se toman en salas de 3 magistrados, mientras que las de unificación las toma la Sala Plena.

${ }^{11}$ COLOMBIA. CORTE CONSTITUCIONAL. C-355 DE 2006. Expediente: D- 6122, 6123 y 6124. (10, mayo, 2006). M.P. Jaime Araujo Rentería [En línea]. [Consultado: marzo 12 de 2020]. Disponible en: https://www.corteconstitucional.gov.co/relatoria/2006/c-355-06.htm

${ }^{12}$ COLOMBIA. CORTE CONSTITUCIONAL. T-209 DE 2008. Expediente T-1673450. (28, febrero, 2008). M.P. Clara Inés Vargas [En línea]. [Consultado: marzo 12 de 2020]. Disponible en: https://www.corteconstitucional.gov.co/relatoria/2008/t-209-08.htm

${ }^{13}$ COLOMBIA. CORTE CONSTITUCIONAL. T-388 DE 2009. Expediente T-1.569.183. (28, mayo, 2009). M.P. Humberto Sierra Porto [En línea]. [Consultado: marzo 12 de 2020]. Disponible en: https://www.corteconstitucional.gov.co/relatoria/2009/t-388-09.htm

${ }^{14}$ COLOMBIA. CORTE CONSTITUCIONAL. SU-096 de 2018. Expediente T-6.612.909. (17, octubre, 2018). M.P. Jose Fernando Reyes Cuartas [En línea]. [Consultado: marzo 12 de 2020]. Disponible en: https://www.corteconstitucional.gov.co/relatoria/2018/SU096-18.htm

${ }^{15}$ Razón de la decisión. Argumentos sin los cuales no se puede llegar a una determinada conclusión. Según la Corte Constitucional (C-539 de 2011) "las consideraciones de la ratio decidendi tienen fuerza vinculante para todas las autoridades públicas"
} 
Cristian Rojas \& Pedro Contreras. Libertad religiosa y objeción de conciencia institucional en Colombia: Un análisis a partir de la sentencia T-738 de 2015.

T-738 de 2015 y en ella se realizaron afirmaciones completamente opuestas a las ya analizadas, a saber:

"Justamente, por la diversidad de ideas y objetivos que aguarda cualquier forma de asociación protegida por el constituyente, aparece ligado a tal derecho el ejercicio de otro tipo de libertades como su correlato. Los sindicatos (art. 39 superior), partidos políticos (art. 40 Ibídem), asociaciones empresariales y mercantiles (arts. 39 y 189-24 ibídem), cooperativas (C.P. arts. 60 y 189-24), establecimientos educativos (C.P. art. 68) y otros cuerpos intermedios de la sociedad civil, no sólo son expresión del derecho de asociación sino que su establecimiento y permanencia implican el ejercicio de derechos como la libertad de conciencia o la libertad religiosa, así como la vigencia del principio de pluralismo jurídico"16.

Aquí la Corte aclara que, uno, las instituciones tienen derechos fundamentales, dos, que entre los derechos que les son reconocidos se encuentra la libertad de conciencia y la libertad religiosa, tres, que este reconocimiento es parte de la protección que recibe a su vez el derecho de asociación y, cuatro, que el ejercicio de la libertad de conciencia y/o la libertad religiosa es esencial a la existencia de estas organizaciones.

Adicionalmente, el Consejo de Estado ${ }^{17}$ en 2016 consideró que las citadas decisiones que niegan la objeción de conciencia a las instituciones "no pueden generalizarse de manera impersonal y abstracta" y consideró que "tampoco en dicho pronunciamiento la Corte Constitucional razona ni fija como regla fundamental o ratio de la decisión la prohibición de

\footnotetext{
${ }^{16}$ COLOMBIA. CORTE CONSTITUCIONAL. T-738 DE 2015. Expediente T-4.970.823. (30, noviembre, 2015). M.P. Luis Guillermo Guerrero [En línea]. [Consultado: marzo 12 de 2020]. Disponible en: https://www.corteconstitucional.gov.co/relatoria/2015/T-738-15.htm El razonamiento responde a una demanda sobre la separación de hermanos en cursos distintos, según las normas del colegio católico La Salle de Medellín.

${ }^{17}$ Máximo tribunal de la jurisdicción contencioso administrativa.
} 
Cristian Rojas \& Pedro Contreras. Libertad religiosa y objeción de conciencia institucional en Colombia: Un análisis a partir de la sentencia T-738 de 2015.

la objeción de conciencia institucional"18. Aunque la sentencia del Consejo de Estado es anterior a la sentencia de unificación, es evidente que los argumentos se aplican de manera idéntica. La SU generaliza el argumento de manera impersonal y abstracta. Además, es claro que la citada afirmación (referida a la objeción de conciencia institucional) es obiter dictum o dicho de paso dentro de la sentencia, ya que nada tiene que ver con el fondo de la materia que se pretendió unificar.

La mencionada postura del Consejo de Estado, de la que se desprende que la aparente prohibición de la objeción de conciencia institucional es obiter dicta, se puede reafirmar con un estudio realizado por Jhohan Córdoba. En él, además de manifestar de manera contundente que no puede ser vinculante, presentó como argumentos dos de los salvamentos que se dieron en el marco de la decisión C-355 de 2006 (sentencia que legalizó el aborto), así:

"Como explicaron los magistrados Marco G. Monroy Cabra y Rodrigo Escobar Gil, la improcedencia de la objeción de conciencia de las instituciones y la aplicabilidad directa o inmediata de la sentencia sin necesidad de reglamentación previa, "no fueron definidos dentro de las deliberaciones que llevaron a la adopción del fallo, como puede corroborarse con la lectura de las actas correspondientes"19.

Ahora bien, las mencionadas decisiones restrictivas tienen dos características comunes. Primero, todas tratan el tema de interrupción voluntaria del embarazo,

\footnotetext{
18 COLOMBIA. CONSEJO DE ESTADO. Sala de lo Contencioso Administrativo Sección Tercera Sentencia 201300257 (13, octubre, 2016). C.P. Guillermo Vargas Ayala [En línea]. [Consultado marzo 12 de 2020] Disponible en:

http://legal.legis.com.co/document/Index?obra=jurcol\&document=jurcol 6f5e3e724bdb482a993df485e44e3 $\underline{54 \mathrm{~b}}$

${ }^{19}$ CÓRDOBA, Jhohan. Objeción de conciencia de las personas organizacionales en Colombia. Revista Ciencias Sociales y educación. Medellín, Colombia: Universidad de Medellín, 2018. No 7 (14). p. 39-64. [Consultado: 20 de noviembre de 2020]. DOI:: https://doi.org/10.22395/csye.v7n14a3
} 
Cristian Rojas \& Pedro Contreras. Libertad religiosa y objeción de conciencia institucional en Colombia: Un análisis a partir de la sentencia T-738 de 2015.

reafirmando el carácter activista que se ha identificado en la Corte colombiana ${ }^{20}$ y que se evidencia cuando asume un compromiso moral en defensa de lo que considera una conquista social (el aborto), superponiéndola a la protección y garantía de otras instituciones ya reconocidas en el ordenamiento colombiano, como lo son la libertad de conciencia y la libertad religiosa. Bajo esta perspectiva, las citadas sentencias omiten un análisis juicioso sobre el ejercicio de la objeción de conciencia en personas jurídicas. Esta primera característica de las sentencias no se abordará a profundidad en el presente artículo, pero se abre la posibilidad de que más adelante se estudien las razones que habrían llevado a la Corte a incurrir en una contradicción y que estarían relacionadas con el activismo judicial.

En segundo lugar, en ninguno de los casos era relevante el ejercicio de derechos por parte de una persona jurídica, por eso, la prohibición de la objeción de conciencia institucional en esas sentencias es obiter dictum y carece de vinculatoriedad. En cambio, en la T 738 de 2015, como el tema sí tenía que ver con el ejercicio de libertades por parte de entidades (supuesta violación de derechos por una norma en el manual de convivencia de un colegio), la afirmación antes citada es parte de la ratio de la decisión, lo que hace que, según lo ha explicado la propia Corte, sí sea vinculante ${ }^{21}$.

Por lo anterior, resulta pertinente realizar una revisión jurisprudencial observando que la línea que se debe adoptar como definitiva es la contenida en la T-738 de 2015. Así, además de la revisión de sentencias nacionales, se acudirá a decisiones de altos tribunales de otros contextos en los que ya se abordó el tema (Chile, Estados Unidos y la Unión Europea) que se pueden usar como referencia para el caso colombiano.

\footnotetext{
${ }^{20}$ GARCÍA, Leonardo, De la "constitucionalización" a la "convencionalización" del ordenamiento jurídico. La contribución del ius constitutionale commune.Revista Derecho del Estado. Bogotá, Colombia: Universidad Externado de Colombia, 2016. No 36 p.131-166. [Consultado: 20 marzo 2020]. DOI:: http://dx.doi.org/10.18601/01229893.n36.05.

${ }^{21}$ COLOMBIA. CORTE CONSTITUCIONAL. SU-354 de 2017. Expediente T-5.882.857. (25, mayo, 2017). M.P. Iván Escrucería [En línea]. [Consultado: marzo 12 de 2020]. Disponible en: https://www.corteconstitucional.gov.co/relatoria/2017/SU354-17.htm
} 
Cristian Rojas \& Pedro Contreras. Libertad religiosa y objeción de conciencia institucional en Colombia: Un análisis a partir de la sentencia T-738 de 2015.

Para ese fin el texto se va a estructurar de esta forma: primero, se revisará lo que ha dicho la jurisprudencia sobre el alcance de los derechos de las personas jurídicas en general; segundo, se revisará en concreto el contenido de las sentencias sobre el derecho a la libertad de conciencia en Colombia; tercero, se realizará un análisis sobre el reconocimiento del derecho de las personas jurídicas a objetar en conciencia. En cuarto lugar, habrá que determinar si, con ese reconocimiento, se están poniendo en riesgo los derechos de terceros. Por último, se presentarán las conclusiones.

\section{DERECHOS FUNDAMENTALES DE LAS PERSONAS JURÍDICAS}

Todas las personas son titulares de derechos y muy pocos distinguen entre personas naturales y jurídicas para su aplicación. Teniendo en cuenta lo anterior hay que preguntarse ¿las personas jurídicas gozan de todos los derechos, incluso los fundamentales? Pues bien, ese es el interrogante que aborda este capítulo.

En 1998 la Corte Constitucional dijo que "hay derechos de las personas jurídicas, que ellas pueden reclamar dentro del Estado Social de Derecho y que las autoridades se obligan a respetar y a hacer que les sean respetados ${ }^{\prime 22}$. Con esa redacción lo primero que da a entender es que, si bien hay derechos que les deben ser reconocidos a las personas jurídicas, no son todos.

22 COLOMBIA. CORTE CONSTITUCIONAL. SU-182 de 1998. Expediente T-141334. (6, mayo, 1998). M. P. Carlos Gaviria Díaz [línea]. [Consultado: marzo 16 de 2020]. Disponible en: https://www.corteconstitucional.gov.co/relatoria/1998/SU182-98.htm 
Cristian Rojas \& Pedro Contreras. Libertad religiosa y objeción de conciencia institucional en Colombia: Un análisis a partir de la sentencia T-738 de 2015.

Ahora, ¿qué pasa con los fundamentales? La misma corporación desde $1992^{23}$ ha manifestado que las personas jurídicas son titulares de derechos fundamentales por dos vías: “a) indirectamente: cuando la esencialidad de la protección gira alrededor de la tutela de los derechos constitucionales fundamentales de las personas naturales asociadas y $b$ ) directamente: cuando las personas jurídicas son titulares de derechos fundamentales no porque actúan en sustitución de sus miembros, sino que lo son por sí mismas, siempre, claro está, que esos derechos por su naturaleza sean ejercitables por ellas mismas."24 Así, se entiende entonces que, por un lado, se habla de los derechos que se les reconocen a las personas jurídicas per se y, por otro, que hay unos derechos que les deben ser reconocidos para proteger a las personas naturales que se puedan ver afectadas.

En otros contextos como Estados Unidos, también está claro el reconocimiento de derechos fundamentales a las personas jurídicas. Es importante mencionar al autor Mark Tushnet quien se pregunta si las sociedades son titulares del derecho a la libertad de conciencia o a la "conciencia religiosa" ${ }^{25} y$, sin pretender dar una respuesta definitiva, analiza los derechos que tienen las corporaciones en el Bill of Rights. De esa forma Tushnet afirma, por ejemplo, que "en un mundo post-Citizens United, sabemos que las corporaciones tienen derechos de libre expresión”26, aunque no sean medios de comunicación. Además de esa sentencia de Citizens United v. Fec ${ }^{27}$, otra de 2018 (NIFLA v. Becerra ${ }^{28}$ ) ratifica la libertad de expresión de personas jurídicas. Así, se observa cómo en Estados Unidos las organizaciones

${ }^{23}$ COLOMBIA. CORTE CONSTITUCIONAL. T-411 de 1992. Expediente № T-785. (17, junio, 1992). M.P. Alejandro Martínez Caballero [En línea]. [Consultado: marzo 16 de 2020]. Disponible en: https://www.corteconstitucional.gov.co/relatoria/1992/t-411-92.htm

${ }^{24}$ Línea que se ha mantenido hasta pronunciamientos más recientes como T- 627 de 2017.

25 TUSHNET, Mark. Do for-profit corporations have rights of religious conscience?. En: Cornell law review. Ithaca, Nueva York: 2013. Vol. 70, nro. 71, p. 70-85. [Consultado: 17 marzo 2020]. Disponible en: https://heinonline.org/HOL/LandingPage?handle=hein.journals/clro2\&div=6\&id=\&page=

${ }^{26}$ Ibid. p. 71. Cita textual: "in a post-Citizens United world, we know that corporations have rights of free expression". Traducción realizada por el autor del presente texto.

27 Para el caso de las corporaciones protegidas por la primera enmienda de la Constitución de Estados Unidos tras el caso de Citizens United, puede consultarse el artículo de Susanna Kim Ripken, Corporate First Amendment Rights after Citizens United: An Analysis of the Popular Movement to End the Constitutional Personhood of Corporations. University of Pennsylvania Journal of Business Law. No. 14, $209-259$ (2011).

${ }^{28}$ Puede hallarse una visión crítica de esta sentencia en el artículo de Claudia E. Haupt, The Limits of Professional Speech. The Yale Law Journal. No. 125 (2018). 
Cristian Rojas \& Pedro Contreras. Libertad religiosa y objeción de conciencia institucional en Colombia: Un análisis a partir de la sentencia T-738 de 2015.

están protegidas por el derecho fundamental consagrado en la primera enmienda de la Constitución.

Sobre esa misma línea, en el contexto europeo y refiriéndose al tema del aborto, la Asamblea Parlamentaria del Consejo de Europa en su Resolución 1763 de 2010 (conocida como Informe McCafferty) ${ }^{29}$ afirmó que "ninguna persona, hospital o institución será coaccionada, considerada civilmente responsable o discriminada debido a su rechazo a realizar, autorizar, participar o asistir en la práctica de un aborto, la realización de un aborto involuntario o de emergencia, eutanasia o cualquier otro acto que cause la muerte de un feto humano o un embrión, por cualquier razón". De esa forma, los avances del derecho estadounidense y europeo en materia de reconocimiento de derechos a personas jurídicas deben ser un referente para Colombia ya que sus argumentos son compatibles con la normativa interna, en concreto con la T-738 de 2015.

Ahora el análisis se centrará en el reconocimiento del derecho a la libertad de conciencia y, naturalmente, la posibilidad de objetar en conciencia de las personas jurídicas.

\section{DERECHO A LA LIBERTAD DE CONCIENCIA EN COLOMBIA}

Desde los inicios de la construcción del Estado de derecho se ha reconocido el derecho a la libertad de conciencia como uno de los más importantes. Puede afirmarse que en el artículo 10 de la Declaración de los Derechos del Hombre y del Ciudadano ${ }^{30}$ e incluso en la primera

\footnotetext{
${ }^{29}$ FRANCIA. ASAMBLEA PARLAMENTARIA DEL CONSEJO DE EUROPA. Resolución 1763. (7, octubre, 2010). Informe McCafferty [En línea]. [Consultado: marzo 18 de 2020]. Disponible en: https://assembly.coe.int/nw/xml/XRef/Xref-XML2HTML-en.asp?fileid=17909\&lang=en

${ }^{30}$ FRANCIA. ASAMBLEA NACIONAL. Declaración de los Derechos del Hombre y del Ciudadano. Artículo 10. (26, agosto,1789) [En línea]. [Consultado: marzo 16 de 2020]. Disponible en: https://www.conseilconstitutionnel.fr/sites/default/files/as/root/bank mm/espagnol/es ddhc.pdf
} 
Cristian Rojas \& Pedro Contreras. Libertad religiosa y objeción de conciencia institucional en Colombia: Un análisis a partir de la sentencia T-738 de 2015.

enmienda del Bill of Rights ${ }^{31}$, se encuentra incorporado el respeto por la libertad de conciencia dada su estrecha relación con la libertad religiosa y de pensamiento. Sin embargo, su consagración expresa llega con el artículo 18 de la Declaración Universal de Derechos Humanos $^{32}$. Posteriormente, en el Convenio Europeo (CEDH, artículo 9) y la Convención Americana sobre Derecho Humanos (CADH, artículo 12) también queda reconocido el derecho a la libertad de conciencia con textos similares: "Toda persona tiene derecho a la libertad de conciencia y de religión"33.

En un análisis casuístico realizado por las autoras María Carmelina Londoño y Juana Inés Acosta, se encuentra que en el sistema interamericano se le dio autonomía a la objeción de conciencia como materialización de las libertades de religión y de conciencia, así: "resulta interesante que la Comisión Interamericana de Derechos Humanos ya lo haya reconocido como un derecho que se deriva de la $\mathrm{CADH}$, y no solo donde aparece expresamente ${ }^{34}$ (artículo 6.3.b), sino también, de manera general, en relación con los derechos a la honra y la dignidad y el derecho a la libertad de conciencia y de religión"35. Igualmente se encuentra que el mismo sistema interamericano exige que el derecho en cuestión sea reconocido en el ordenamiento interno de cada Estado, como ocurre en Colombia en donde tiene rango constitucional ${ }^{36}$.

${ }^{31}$ ESTADOS UNIDOS DE AMÉRICA. CONGRESO DE LOS ESTADOS UNIDOS. Bill of rights. (25, septiembre, 1789). [En línea]. [Consultado: marzo 20 de 2020]. Disponible en: https://billofrightsinstitute.org/foundingdocuments/bill-of-rights/

32 FRANCIA. Declaración Universal de los Derechos Humanos. Artículo 18. (10, diciembre,1948) [En línea]. [Consultado: marzo 20 de 2020]. Disponible en: https://www.un.org/es/universal-declaration-human-rights/

${ }^{33}$ COSTA RICA, ORGANIZACIÓN DE ESTADOS AMERICANOS. Convención Americana sobre Derechos Humanos. (22, noviembre,1969) [En línea]. [Consultado: abril 10 de 2020]. Disponible en: https://www.oas.org/dil/esp/tratados b-32 convencion americana sobre derechos humanos.htm

${ }^{34}$ Esto es, en lo que se refiere a la prestación del servicio militar obligatorio.

35 LONDOÑO, María y ACOSTA, Juana, La protección internacional de la objeción de conciencia: análisis comparado

entre sistemas de derechos humanos y perspectivas en el sistema interamericano. Anuario Colombiano de Derecho

Internacional. Bogotá, Colombia: Universidad del Rosario, 2015. Vol. 9,p. 240. [Consultado: 20 marzo 2020]. DOI: http://dx.doi.org/10.12804/acdi9.1.2016.07. Disponible en: https://revistas.urosario.edu.co/index.php/acdi/article/view/4497/3227

${ }^{36}$ Teniendo en cuenta que Colombia es parte de la CADH, las disposiciones en ella contenidas, por tratar el tema de derechos humanos, forman parte del Bloque de Constitucionalidad en sentido estricto, lo que significa que son normas con rango constitucional. 
Cristian Rojas \& Pedro Contreras. Libertad religiosa y objeción de conciencia institucional en Colombia: Un análisis a partir de la sentencia T-738 de 2015.

En el contexto colombiano el reconocimiento del derecho a la objeción de conciencia y sus límites, tiene coincidencias importantes con el derecho internacional. Los pronunciamientos de la Corte Constitucional sobre objeción de conciencia iniciaron en 1992 con la sentencia T-409 que trata sobre la no prestación del servicio militar por motivos religiosos. En ella la Corte se mostró bastante exigente con los requisitos para el reconocimiento de su ejercicio. Cristina Pardo Schlesinger (hoy magistrada de la Corte Constitucional) en su artículo "La objeción de conciencia en la jurisprudencia de la Corte Constitucional colombiana"37, hace un recuento histórico hasta 2005 de la jurisprudencia de la Corte con respecto a la libertad de conciencia. En él se observa que los pronunciamientos han sido en materia de servicio militar, salud, educación, obligación de prestar juramento y obligaciones laborales. Hasta ese año el reconocimiento y desarrollo del derecho era mínimo.

Es a partir de 2009 que comienza un desarrollo realmente significativo del derecho con la sentencia C-728 de $2009^{38}$, en la que se habla sobre el reconocimiento efectivo del derecho a la libertad de conciencia, lo define y empieza a darle su alcance. Además, exhorta al Congreso de la República a legislar al respecto ${ }^{39}$. Se explicó que la objeción de conciencia "supone la presencia de una discrepancia entre la norma jurídica y alguna norma moral, siendo reconocido por la Corte que es posible objetar por razones de conciencia deberes laborales, educativos y profesionales".

\footnotetext{
${ }^{37}$ PARDO, Cristina. La objeción de conciencia en la jurisprudencia de la corte constitucional colombiana. Revista Persona y Bioética. En: Bogotá Colombia: 2006. Vol. 10, nro. 1, p. 52-68. [Consultado: 17 marzo 2020]. Disponible en: https://personaybioetica.unisabana.edu.co/index.php/personaybioetica/article/view/928/1008 ${ }_{38}$ COLOMBIA. CORTE CONSTITUCIONAL. C-728 de 2009. Expediente D-7685. (14, octubre, 2009). M.P. Gabriel Eduardo Mendoza Martelo [En línea]. [Consultado: marzo 20 de 2020]. Disponible en: https://www.corteconstitucional.gov.co/relatoria/2009/C-728-09.htm

${ }^{39}$ El Congreso de la República no ha emitido una ley estatutaria para regular el derecho en mención, sin embargo, el artículo 85 de la Constitución lo incluye dentro de los derechos de aplicación inmediata, que según la Corte Constitucional (T-406 de 1992) son derechos que no necesitan reglamentación para ser efectivos.
} 
Cristian Rojas \& Pedro Contreras. Libertad religiosa y objeción de conciencia institucional en Colombia: Un análisis a partir de la sentencia T-738 de 2015.

En materia de educación, fue en $1998^{40}$ que se comenzó a darle el tratamiento adecuado. En palabras de Cristina Pardo: “Nótese cómo en este caso la Corte avanzó en el respeto de la conciencia individual, validando la objeción, y acudió a un criterio de armonización que permitiera el ejercicio tanto de la libertad de conciencia, como de la libertad de cátedra". ${ }^{41}$ Si bien este ya fue un avance comparado con los pronunciamientos anteriores, todavía faltaba mucho por desarrollar. Más adelante (en 2005²) la Corte hace un cambio de jurisprudencia y reconoce la objeción de conciencia en materia de educación con respecto a temas en los que se había rehusado a reconocerla antes.

La importancia de la objeción de conciencia de personas naturales recobra importancia con la Sentencia SU-108 de 2016"3, expresando que "El reconocimiento a la objeción de conciencia se encuentra intrínsecamente relacionado con el derecho a la libertad de conciencia y no se constituye en una evasión al ordenamiento jurídico, sino que, por el contrario, toda sociedad democrática debe estar interesada en el respeto de los derechos individuales de cada uno de los ciudadanos". Y añade que "Tres prerrogativas nacen del derecho a la libertad de conciencia: (i) nadie podrá ser objeto ni de acoso ni de persecución en razón de sus convicciones o creencias; (ii) ninguna persona estará obligada a revelar sus convicciones y (iii) nadie será obligado a actuar contra su conciencia".

En esa línea garantista, en 2018 la Corte Constitucional ${ }^{44}$ resuelve una tutela interpuesta por dos ciudadanos cuya religión choca con la prestación del servicio militar,

40 COLOMBIA. CORTE CONSTITUCIONAL. T-588 de 1998. Expediente T-173807. (20, octubre, 1992). M.P. Eduardo Cifuentes Muñoz [En línea]. [Consultado: abril 12 de 2020]. Disponible en: https://www.corteconstitucional.gov.co/relatoria/1998/t-588-98.htm

${ }^{41}$ PARDO. Op. Cit., p. 61.

42 COLOMBIA. CORTE CONSTITUCIONAL.T-026 de 2005. Expediente T-924708. (20, enero, 2005). M.P. Humberto Sierra Porto [En línea]. [Consultado: abril 10 de 2020]. Disponible en: https://www.corteconstitucional.gov.co/relatoria/2005/T-026-05.htm

${ }^{43}$ COLOMBIA. CORTE CONSTITUCIONAL.SU-108 de 2016. Expedientes T-2.643.585 y T-2.652.480 AC. (03, marzo, 2016). M.P. Alberto Rojas Ríos [En línea]. [Consultado: marzo 21 de 2020]. Disponible en: https://www.corteconstitucional.gov.co/relatoria/2016/SU108-16.htm

44 COLOMBIA. CORTE CONSTITUCIONAL. T-353 de 2018. Expedientes acumulados T-6.367.365 y T-6.372.321. (31, agosto, 2018). M.P. Alberto Rojas Ríos [En línea]. [Consultado: marzo 21 de 2020]. Disponible en: https://www.corteconstitucional.gov.co/relatoria/2018/T-353-18.htm 
Cristian Rojas \& Pedro Contreras. Libertad religiosa y objeción de conciencia institucional en Colombia: Un análisis a partir de la sentencia T-738 de 2015.

afirmando que "actuar según los dictados de la conciencia, en libertad, es un presupuesto de la construcción de una sociedad democrática". El tribunal es claro en afirmar que "se ha de conceder el derecho de objeción de conciencia cuando sea irrazonable y desproporcionado imponer a una persona actuar contra sus creencias profundas y sinceras, sean o no de carácter religioso". Esta posición se reafirmó también en $2019^{45}$.

En materia de prestaciones laborales la controversia no es muy relevante. En la que sí vale la pena detenerse es en materia de salud. El primer debate sobre el derecho en este campo giraba en torno a las transfusiones de sangre de los testigos de Jehová y la Corte principalmente sostuvo que "la decisión de no aceptar la transfusión de sangre constituía un acto razonado y legítimo del accionante, en tanto que era voluntario, realizado en ejercicio de la autonomía, en acatamiento de su creencia religiosa y en el pleno ejercicio de sus derechos fundamentales a la libertad de conciencia, libre desarrollo de la personalidad y libertad de cultos ${ }^{\prime \prime 6}$, siempre que no esté en juego la vida de un menor de 14 años.

Es a partir de 2006 donde se abre un nuevo debate en cuanto a objeción de conciencia en temas de salud con la sentencia C-355 de 2006 que, con respecto al aborto, reconoce a los médicos la posibilidad de objetar cuando no se trata de una mera opinión o del desconocimiento de derechos de terceros. Además, advierte que "la objeción de conciencia no es un derecho del cual son titulares las personas jurídicas o el Estado. Solo es posible reconocerlo a personas naturales ${ }^{47 \prime \prime}$, lo que quiere decir que también fue la primera en plantear la discusión sobre objeción de conciencia institucional en Colombia. Bajo esta consideración, el Hospital San Ignacio de la Pontificia Universidad Javeriana fue sancionado en 2009 por negarse a practicar un aborto dentro de las causales despenalizadas en la citada

\footnotetext{
${ }^{45}$ COLOMBIA. CORTE CONSTITUCIONAL.C-370 de 2019. Expediente D-12372. (14, agosto, 2019). M.P. Gloria Stella Ortiz [En línea]. [Consultado: abril 12 de 2020]. Disponible en:https://www.corteconstitucional.gov.co/relatoria/2019/C-370-19.htm

${ }^{46}$ PARDO. Op. Cit. p. 66

${ }^{47}$ CORTE CONSTITUCIONAL. C- 355 de 2006. Op. Cit.
} 
Cristian Rojas \& Pedro Contreras. Libertad religiosa y objeción de conciencia institucional en Colombia: Un análisis a partir de la sentencia T-738 de 2015.

sentencia, aunque el centro médico alega que no se negó al procedimiento bajo el argumento de la objeción de conciencia institucional ${ }^{48}$.

Esta línea argumentativa la ha mantenido la Corte cuando ha tratado el tema del aborto. A propósito de dos tutelas posteriores en ese sentido el Consejo de Estado en 2016, con la sentencia ya citada en la parte introductoria, consideró que lo que dijo la Corte en materia de objeción de conciencia institucional son argumentos obiter dicta. Esta consideración hizo parte de la decisión para la nulidad parcial de una circular de la Superintendencia de Salud ${ }^{49}$ demandada por el Hospital San Ignacio.

A pesar de eso, de manera paralela durante el desarrollo jurisprudencial del derecho, apareció la mencionada tutela T-738 de 2015 que sí reconoció la libertad de conciencia de manera expresa a varios tipos de instituciones y formas de asociación en la ratio de la decisión, por lo que es vinculante. Debe entenderse que la protección de esta libertad a las personas jurídicas se tiene que garantizar igual que a los individuos en las sentencias revisadas en este apartado, entre otras razones porque su finalidad es protegerlos a ellos y a sus derechos.

\section{OBJECIÓN DE CONCIENCIA DE LAS PERSONAS JURIIDICAS}

De entrada, hay que afirmar que la sentencia de 2015 es poco conocida por los doctrinantes colombianos. En general, la discusión sobre la objeción de conciencia

\footnotetext{
${ }^{48}$ Las declaraciones entregadas por el director del Hospital San Ignacio, Julio César Castellanos, a Blu Radio el 17 de enero de 2017, puede encontrarse en el siguiente link: https://www.bluradio.com/nacion/ni-hemospracticado-ni-haremos-abortos-voluntarios-director-hospital-san-ignacio-127711

${ }^{49}$ COLOMBIA. SUPERINTENDENCIA DE SALUD. Circular 003 de 2013 (29, abril, 2013). [En línea]. Informe Por la cual se imparten instrucciones sobre la interrupción voluntaria del embarazo (IVE), en aplicación de la Constitución Política de Colombia, los tratados internacionales y las sentencias de la Corte Constitucional, y se deroga la Circular número 03 de noviembre de 2011. Diario Oficial No. 48.776 de 29 de abril de 2013. [Consultado: marzo 26 de 2020]. Disponible https://docs.supersalud.gov.co/PortalWeb/Juridica/OtraNormativa/C SNS 0003 2013.pdf
} 
Cristian Rojas \& Pedro Contreras. Libertad religiosa y objeción de conciencia institucional en Colombia: Un análisis a partir de la sentencia T-738 de 2015.

institucional se ha abordado desde la perspectiva del aborto y la doctrina colombiana no es unánime con respecto a la postura que se debe adoptar.

Por un lado, autores como Vicente Prieto, han hablado sobre la conciencia que poseen las instituciones "por analogía con las personas naturales" y como "modo de garantizar que la entidad pueda constituirse y actuar de conformidad con un ideario propio, que compromete toda su actividad de acuerdo con determinados ideales éticos o religiosos" ${ }^{50}$. Esto, sumado a las consideraciones de Jhohan Córdoba en las que cita a Vicente Prieto afirmando que "la objeción de conciencia institucional es una proyección de la objeción de conciencia individual" 51 y junto con los argumentos que presentó para sostener que la prohibición de la objeción hecha por la Corte no es vinculante, permite mostrar que hay un análisis de la doctrina que respalda el contenido de la sentencia de 2015.

Por otra parte, hay autores que sostienen la tesis contraria al considerar que no puede extenderse a las personas jurídicas la conciencia que es propia de las personas naturales. Sobre el caso de Colombia y en relación con las "barreras" para la práctica del aborto, Ana Cristina González Vélez habla de las situaciones en las que se busca contar "con permisos para ampliar la objeción a las instituciones como un todo, contrariando el fundamento principal de la objeción que es la existencia de una conciencia que no tienen las instituciones" ${ }^{\prime 52}$. En ese análisis la investigadora no considera la existencia de derechos fundamentales de las instituciones y su relación con los derechos de las personas naturales.

\footnotetext{
50 PRIETO, Vicente.La objeción de conciencia en instituciones de salud. (Colombia).Editorial Temis SA y Universidad de La Sabana, 2013. ISBN: 2655201300026500.

PRIETO, Vicente. Dimensiones individuales e institucionales de la objeción de conciencia al aborto. Revista general de derecho canónico y derecho eclesiastico del Estado. En: Bogotá Colombia: 2012. Vol. 30, p. 1-64. [Consultado: 20 noviembre 2020]. Disponible en: https://dialnet.unirioja.es/servlet/articulo?codigo=4067418

${ }^{51}$ CÓRDOBA, Jhohan. Objeción de conciencia de las personas organizacionales en Colombia. Revista Ciencias Sociales y educación. Medellín, Colombia: Universidad de Medellín, 2018. No 7 (14). p. 39-64. [Consultado: 20 de noviembre de 2020]. DOI:: https://doi.org/10.22395/csye.v7n14a3

52 González, Ana. Objeción de conciencia, bioética y derechos humanos: una perspectiva desde Colombia. Revista Revista Bioética y derecho. Barcelona, España, 2018. No. 42 p. 106-126 (Consultado 16 de noviembre de 2020). http://scielo.isciii.es/scielo.php?pid=S1886-58872018000100008\&script=sci arttext\&tlng=pt
} 
Cristian Rojas \& Pedro Contreras. Libertad religiosa y objeción de conciencia institucional en Colombia: Un análisis a partir de la sentencia T-738 de 2015.

Esa misma línea de interpretación estuvo presente en el Segundo Seminario Regional Latinoamericano, cuyo tema fue “¿Objeción de conciencia institucional? Impacto en la prestación de servicios de interrupción voluntaria del embarazo", convocado por organizaciones defensoras del aborto. En sus memorias se afirmó: "si bien las voces mayoritarias del seminario consideraron que la objeción de conciencia institucional no es legítima, ni ética ni legal, una voz minoritaria planteó que la misión de una institución puede considerarse un equivalente de la conciencia individual de una persona natural." 53 La posición mayoritaria del evento, además, se basó en la afirmación tajante de que "la Corte constitucional de Colombia, estableció que la objeción de conciencia no es un derecho de las personas jurídicas", sin abordar el problema de la no vinculatoriedad de las consideraciones que el tribunal hizo al respecto. Nuevamente se observa, en este caso desde la doctrina, que las visiones restrictivas aparecen en el contexto de la práctica del aborto.

Vista la discusión al interior de Colombia, vale la pena dar una mirada al contexto internacional, particularmente a las jurisdicciones que resolvieron el tema de la objeción de conciencia institucional en la línea que adopta la sentencia de 2015.

En países como Estados Unidos y Chile ya ha sido reconocida la libertad religiosa de las instituciones y su derecho a objetar en conciencia. Burwell v. Hobby Lobby es la sentencia hito de 2011 que determinó que una empresa estadounidense podía negarse a pagar servicios del sistema de salud contrarios a sus convicciones en el seguro de sus empleados, con base en el "Religious Freedom Restoration Act (RFRA)" 54.

\footnotetext{
${ }^{53}$ González, Ana. Memorias del Segundo Seminario Regional Latinoamericano, “¿Objeción de conciencia institucional? Impacto en la prestación de servicios de interrupción voluntaria del embarazo". Bogotá, Colombia, 2017. Consultado el 19 de noviembre de 2020. http://www.codajic.org/sites/www.codajic.org/files/Memorias Seminario Objecion de Conciencia.pdf

${ }^{54}$ ESTADOS UNIDOS. CORTE SUPREMA DE JUSTICIA. Burwell vs Hobby Lobby. 573 U.S. 682 (30, junio 2011) Autor de la opinión mayoritaria, Samuel Alito [En línea]. [Consultado: marzo 26 de 2020 ] Disponible en: https://www.supremecourt.gov/opinions/13pdf/13-354 olp1.pdf
} 
Cristian Rojas \& Pedro Contreras. Libertad religiosa y objeción de conciencia institucional en Colombia: Un análisis a partir de la sentencia T-738 de 2015.

Entre las consideraciones más importantes de la sentencia está la siguiente: "El texto del RFRA's muestra que el Congreso diseñó el estatuto para otorgar una amplia protección de la libertad religiosa (...) Utilizó la ficción legal común de incluir a las corporaciones dentro de la definición de personas del RFRA's, pero el propósito de extender los derechos a las corporaciones es proteger los derechos de las personas asociadas con la corporación (...)"55. Se evidencia cómo ese argumento es totalmente compatible con los que utiliza la Corte en Colombia para reconocerle derechos a las personas jurídicas por vía indirecta.

Alrededor de estas decisiones se han generado comentarios que suscitan una discusión académica. La sentencia del caso Hobby Lobby ha resultado polémica como toda landmark decision. El profesor de la Universidad de Yale, Douglas NeJaime, considera que la sentencia excede todos los precedentes ${ }^{56}$, pues ya no se trataría de proteger la libertad religiosa, sino de convertir esta libertad en la posibilidad de abstenerse de ser "cómplice" de quienes viven según otras convicciones.

A esa crítica responde el experto en libertad religiosa Douglas Laycock ${ }^{57}$, afirmando que NeJaime se equivoca cuando cree que la libertad post Hobby Lobby es una ventaja para los conservadores religiosos en detrimento de quienes tienen visiones de la vida más progresistas, pues ellos también tienen reproches morales frente a los conservadores a quienes suelen identificar como "fanáticos llenos de odio y extremistas intransigentes", y añade que "La mutua desaprobación moral es inherente a una sociedad moralmente

\footnotetext{
${ }^{55}$ Ibid. Cita textual: "Congress designed the statute to provide very broad protection for religious liberty and did not intend to put merchants to such a choice. It employed the familiar legal fiction of including corporations within RFRA's definition of "persons", but the purpose of extending rights to corporations is to protect the rights of people associated with the corporation, including shareholders, officers, and employees". Traducción realizada por el autor del presente texto.

${ }^{56}$ NEJAIME, Douglas y SIEGEL, Reva. Conscience Wars: Complicity-based Conscience Claims in religion and politics. En: The Yale Law Journal. New Haven, Connecticut: 2014. Vol. 124, nro. 7, p. 2516-2591. [Consultado: 17 marzo 2020]. Disponible en: https://www.yalelawjournal.org/feature/complicity-based-conscience-claims

57 LAYCOCK, Douglas. Religious Liberty for Politically Active Minority Groups: A Response to NeJaime and Siegel. The Yale Law Journal Forum, New Haven, Connecticut: 2016. nro. 125, p. 369-389. [Consultado: 17 marzo 2020]. Disponible en: https://www.yalelawjournal.org/pdf/Laycock PDF wgmv6xbh.pdf

Cita textual: "hate-filled bigots and extremists zealots". "Mutual moral disapproval is inherent in a morally pluralistic society". "offensiveness is not a sufficient reason for suppressing speech". Traducción realizada por el autor del presente texto.
} 
Cristian Rojas \& Pedro Contreras. Libertad religiosa y objeción de conciencia institucional en Colombia: Un análisis a partir de la sentencia T-738 de 2015.

pluralista". Además, considera que el daño que pueden causar las libertades como la de Hobby Lobby no ameritan su prohibición, así como en la libertad de expresión "la ofensa no es razón suficiente para suprimir el discurso".

Otra crítica viene de la profesora Elizabeth Sepper ${ }^{58}$, quien considera que la sentencia de Hobby Lobby supone el regreso del Lochnerism: la "era Lochner" (por Lochner v. New York) es un periodo de la historia de la Corte Suprema de Estados Unidos en la que se derribaron muchas regulaciones de la actividad económica, pero en ese escenario de libre mercado se presentaron abusos corporativos. Sin embargo, Sean Nade ${ }^{59}$, de la Universidad de Columbia, se aparta de esa visión pues considera que la sentencia no extiende la interpretación del libre ejercicio de la religión, sino que extiende dicha libertad a las personas jurídicas y por eso el debate debe centrarse en el carácter de persona que tienen las corporaciones.

Con todo y las referidas críticas, la Corte estadounidense ha mantenido y reafirmado el precedente de Hobby Lobby. En julio de 2020. al resolver el caso denominado Little Sisters of the Poor v. Pensilvania, la Corte afirmó: "Nosotros sostenemos que los Departamentos (encargados de administrar el Affordable Care Act) tienen la autoridad para otorgar excepciones a los requisitos de la regulación de los contraceptivos para empleadores con objeciones religiosas y de conciencia"60 (paréntesis fuera del texto original). De esta manera, se entiende que los argumentos que buscan derrotar la postura adoptada en 2011 no han tenido éxito y hoy las personas que conforman las organizaciones se mantienen protegidas.

\footnotetext{
${ }^{58}$ SEPPER, Elizabeth. Free Exercise Lochnerism. Columbia Law Review Nueva York, Nueva York: 2015. Vol. 115, p.1453-1519. [Consultado: 12 febrero 2020]. Disponible en: https://columbialawreview.org/wpcontent/uploads/2016/02/October-2015-7-Sepper UPDATE.pdf

${ }^{59}$ NADEL, Sean. Closely Held Conscience: Corporate Personhood in the Post-Hobby Lobby World. Columbia Journal of Law, Nueva York: 2016. Vol. 50, p.417 448. [Consultado: 12 febrero 2020]. Disponible en: http://jlsp.law.columbia.edu/wp-content/uploads/sites/8/2017/05/50-Nadel.pdf

${ }^{60}$ ESTADOS UNIDOS. CORTE SUPREMA DE JUSTICIA. Little Sisters of the Poor v. Pensilvania. 591 U.S. (06, julio 2020) Autor de la opinión mayoritaria, Clarence Thomas [En línea]. [Consultado: noviembre 18 de 2020 ] Disponible en: https://www.supremecourt.gov/opinions/19pdf/19-431 5i36.pdf
} 
Cristian Rojas \& Pedro Contreras. Libertad religiosa y objeción de conciencia institucional en Colombia: Un análisis a partir de la sentencia T-738 de 2015.

En el caso de Chile el Tribunal Constitucional| ${ }^{61}$, en el marco de la discusión sobre la ley de aborto, analizó la posibilidad de que las instituciones pudieran objetar en conciencia y consideró que "la objeción de conciencia, en la forma planteada por el proyecto de ley (...), debe entenderse amparada por la dignidad de las personas que, individualmente o proyectada en su asociación con otros, se niegan a practicar cierto tipo de actuaciones, por razones éticas, morales, religiosas, profesionales, u otras de señalada relevancia".

Se observa cómo el tribunal chileno, además de compartir la idea de proteger los derechos fundamentales de las personas naturales que conforman una persona jurídica, da a entender que no respetar el derecho a la libertad de conciencia institucional, puede generar una vulneración injustificada al derecho de libre asociación. En el caso colombiano, se estaría menoscabando el derecho contenido en el artículo 38 de la Constitución del 91 y es por esto que, bajo la misma lógica, la Corte colombiana en la T-738 de 2015 protege la libertad de conciencia en el marco del ejercicio del derecho de asociación, así como el de libertad religiosa.

En el contexto chileno autores como Alexander Nuñéz y Javiera Cabello se han mostrado en contra de la decisión, considerando que, como hay elementos jurisprudenciales que le han dado el carácter de interés general a la salud, su garantía debe estar por encima de la autonomía de las instituciones que se encuentran imposibilitadas para objetar en conciencia en lo que se refiere a la práctica del aborto ${ }^{62}$. En contraste, desde el Instituto de Estudios de la Sociedad, también en Chile, consideran que "en principio ningún centro privado de salud tiene la obligación de ofrecer prestaciones específicas (ni aborto ni ninguna otra), pero las entidades particulares que participan de la red pública de salud sí pueden

\footnotetext{
${ }^{61}$ CHILE. TRIBUNAL CONSTITUCIONAL CHILENO. Sentencia rol N³729 (3751)-17 (21, agosto, 2017) [En línea]. [Consultado: marzo 26 de 2020 ] Disponible en: https://www.law.utoronto.ca/utfl file/count/documents/reprohealth/chile-2017-sintesis-spanish.pdf

${ }^{62}$ NÚÑEZ, Alexander y CABELLO, Javiera. Objeción de conciencia institucional y regulación en salud: ¿existe una excusa legítima frente al aborto en Chile? Revista de Bioética y Derecho Barcelona: 2018. No 43, p.162-177. [Consultado: 12 mayo 2020]. DOI: https://doi.org/10.1344/rbd2019.0.204122
} 
Cristian Rojas \& Pedro Contreras. Libertad religiosa y objeción de conciencia institucional en Colombia: Un análisis a partir de la sentencia T-738 de 2015.

verse en la necesidad de objetar ante una solicitud de aborto. Ello dependerá precisamente de su ideario institucional"63.

Si bien el propósito no era ahondar en estas discusiones internacionales, al revisarlas se encuentra que los pronunciamientos de la Corte colombiana recogen de manera pertinente argumentos similares para que se le reconozca la libertad de conciencia a las instituciones. Por un lado, la protección indirecta de la que habla la sentencia T-411 de 1992 contiene el argumento de Burwell v. Hobby Lobby de proteger a las personas naturales que conforman la persona jurídica y, por otro lado, la T-738 de 2015 fija en Colombia el reconocimiento de la libertad de conciencia institucional para proteger la libre asociación, tal y como lo hace el tribunal chileno. Este último argumento refleja la protección directa de las libertades de conciencia y de religión de las personas jurídicas pues, como dice la misma sentencia colombiana, así se garantizan los fines que "en últimas, justifican la existencia de aquellos cuerpos comunitarios".

\section{LÍMITES A LA LIBERTAD DE CONCIENCIA QUE EVITAN EL MENOSCABO DE OTROS DERECHOS}

En el ya citado artículo, Londoño y Acosta afirman que "en las más recientes decisiones, los tribunales y órganos competentes en los dos sistemas (europeo y universal) han declarado explícitamente que la objeción de conciencia no está sujeta al margen de apreciación de los Estados de manera irrestricta, por lo que se han establecido los mismos límites que operan frente a otros derechos. Es en este sentido que, en particular el TEDH, ha

${ }^{63}$ ALVARAdO, Claudio, CONTRERAS, Fernando, SVENSSON, Manfred. Objeción de conciencia institucional. Cuatro claves para el debate. Claves para el debate. Santiago de Chile: 2018. No 1, p 1-10. [Consultado: 12 mayo 2020]. Dsiponible en: https://www.ieschile.cl/wp-content/uploads/2018/07/Objecio\%CC\%81n-de-concienciainstirucional-4-claves-para-el-debate.pdf 
Cristian Rojas \& Pedro Contreras. Libertad religiosa y objeción de conciencia institucional en Colombia: Un análisis a partir de la sentencia T-738 de 2015.

acudido al test de proporcionalidad"64 (paréntesis fuera del texto original). Dicho test se encuentra en el mismo artículo $9^{\circ}$ del Convenio Europeo de Derechos Humanos: la libertad que allí se protege no puede ser objeto de restricciones que no estén previstas en la ley y sean necesarias en una sociedad democrática para proteger la seguridad, el orden, la salud o la moral públicos, o para la protección de los derechos y las libertades de los demás. Una redacción casi idéntica puede encontrarse en el artículo 12 de la $\mathrm{CADH}^{65}$.

En Colombia también se ha aclarado que el derecho a objetar no es absoluto y para estudiar sus límites es necesario revisar la sentencia T-388 de 200966. Allí se establecen dos restricciones en la línea de la C-355 de 2006 que pueden resumirse de la siguiente manera: (1) la objeción no puede ser resultado de la simple opinión o arbitrariedad del médico, y (2) no puede suponer la afectación grave del derecho fundamental de un tercero. Pero la Corte no pretende hacer una delimitación exhaustiva del derecho, por eso explica que, si bien "parece posible sentar algunas pautas orientadoras, el derecho a alegar la inobservancia de un deber jurídico por motivos de conciencia debe ser analizado a la luz de las exigencias de cada caso en concreto".

Observando estos límites y trayendo el debate norteamericano al contexto nacional, la crítica de NeJaime sobre una ventaja conservadora para evadir responsabilidades frente a terceros no se sostendría porque, como se dijo en el párrafo anterior, la objeción de conciencia no puede suponer la afectación grave a derechos fundamentales de otros. En en el ordenamiento colombiano ya hay una protección frente a los eventuales "excesos" que denuncia el autor.

Colombia tampoco estaría expuesta al "lochnerismo" del que habla Sepper si se reconoce la objeción de conciencia institucional, pues el ordenamiento no otorga esos

\footnotetext{
${ }^{64}$ LONDOÑO y ACOSTA. Op. Cit. p. 266

${ }^{65}$ ORGANIZACIÓN DE ESTADOS AMERICANO. Op. Cit.. Artículo 12: "toda persona tiene derecho a la libertad de conciencia y de religión".

${ }^{66}$ CORTE CONSTITUCIONAL. T-388 de 2009. Op. Cit.
} 
Cristian Rojas \& Pedro Contreras. Libertad religiosa y objeción de conciencia institucional en Colombia: Un análisis a partir de la sentencia T-738 de 2015.

márgenes de libertad económica y la Corte Constitucional ${ }^{67}$ ha aclarado, por ejemplo, que cuando se trata de servicios públicos, el Estado puede delimitar el alcance de la libertad de empresa cuando son prestados a través de particulares, siguiendo el artículo 333 de la Constitución Política ${ }^{68}$.

Así las cosas, se puede afirmar que reconocer el derecho fundamental a objetar en conciencia a las personas jurídicas no pone en riesgo a otros. Esto bajo el entendido de que ninguna libertad es absoluta y, por tanto, se encuentra limitada por la no afectación grave de los derechos fundamentales de terceros.

\section{CONCLUSIÓN}

Hecha la revisión jurisprudencial, se observa que la Corte Constitucional colombiana ha sostenido dos posturas contradictorias con respecto al reconocimiento del derecho a la objeción de conciencia de las personas jurídicas, sin embargo, solo la T-738 de 2015 es vinculante y es la que se debe reafirmar. Hoy el debate no se encuentra resuelto del todo, un juez fácilmente se encuentra con ambas posturas y puede no tener claridad sobre el sentido que debe darle a su fallo, entre otras cosas, porque el pronunciamiento más reciente es una sentencia de unificación que niega el derecho a las personas jurídicas, aunque lo haga como un dicho de paso (obiter dictum).

El argumento que ha presentado la Corte para no reconocer el derecho, es que nunca se pueden transmitir caracteres morales propios de las personas naturales a las personas

67 COLOMBIA. CORTE CONSTITUCIONAL.C-263 de 2013. Expediente D-93297. (8, mayo, 2013). M.P. Jorge Iván Palacio [En línea]. [Consultado: abril 12 de 2020]. Disponible en: https://www.corteconstitucional.gov.co/RELATORIA/2013/C-263-13.htm

${ }^{68}$ ASAMBLEA NACIONAL CONSTITUYENTE. Op. Cit. Artículo 333. 
Cristian Rojas \& Pedro Contreras. Libertad religiosa y objeción de conciencia institucional en Colombia: Un análisis a partir de la sentencia T-738 de 2015.

jurídicas, pero la propia Corte ha reconocido el derecho que estas tienen al buen nombre ${ }^{69}$ que debe ser protegido como parte del patrimonio moral de las personas ${ }^{70}$. Lo anterior demuestra que la primera afirmación no es acertada, ya que en otras ocasiones la misma Corporación ha otorgado caracteres morales propios de personas naturales a personas jurídicas. Además, ese argumento olvida lo afirmado por la propia Corte y que ya se ha explicado en este texto: que no solo se reconocen los derechos fundamentales de las personas jurídicas directamente, sino cuando se busca tutelar los de las personas naturales asociadas, lo que significa que no es necesario "transmitir" características de las personas naturales a las jurídicas, es suficiente con reconocer los derechos de esas personas naturales y la necesidad de protegérselos cuando se asocian.

Cada vez que la Corte afirma que no hay lugar a reconocer el derecho a las instituciones, desconoce su propia jurisprudencia sobre los derechos de las personas jurídicas y el precedente vinculante plasmado en la tutela de 2015. De hecho, lo que demuestra es que hay un afán por reafirmar una postura favorable a la interrupción voluntaria del embarazo, restándole rigor al estudio de derechos de enorme relevancia como la libertad religiosa y la libertad de conciencia.

Igualmente deja de lado una realidad fáctica innegable que demuestra que a las personas naturales se les ha venido vulnerando su libertad religiosa y de conciencia cuando ejercen su derecho a la libre asociación, en contraste con los avances que se han dado en otros países.

Por todo lo anterior se debe adoptar de manera definitiva la postura en la que sí se le reconoce el derecho a la libertad de conciencia, consagrado en el artículo 18 de la

${ }^{69}$ COLOMBIA. CORTE CONSTITUCIONAL. Expediente T-6.467.142. (26, junio, 2018). M.P. Gloria Stella Ortíz [En línea]. [Consultado: abril 12 de 2020]. Disponible en: https://www.corteconstitucional.gov.co/relatoria/2018/T238-18.htm

70 COLOMBIA. CORTE CONSTITUCIONAL.C-489 de 2002. Expediente D-3838. (26, junio, 2002). M.P.Rodrigo Escobar Gil [En línea]. [Consultado: abril 12 de 2020]. Disponible en: https://www.corteconstitucional.gov.co/relatoria/2002/C-489-02.htm 
Cristian Rojas \& Pedro Contreras. Libertad religiosa y objeción de conciencia institucional en Colombia: Un análisis a partir de la sentencia T-738 de 2015.

Constitución Política de Colombia, a las personas jurídicas. Esto para garantizar la libertad de conciencia de las personas naturales que las conforman y para no generar un perjuicio al ejercicio legítimo de la libre asociación.

\section{BIBLIOGRAFÍA}

1. AlVARADO, Claudio, CONTRERAS, Fernando, SVENSSON, Manfred. Objeción de conciencia institucional. Cuatro claves para el debate. Claves para el debate. Santiago de Chile: 2018. No 1, p 1-10. [Consultado: 12 mayo 2020]. Disponible en: https://www.ieschile.cl/wp-content/uploads/2018/07/Objecio\%CC\%81n-deconciencia-instirucional-4-claves-para-el-debate.pdf

2. BERLIN, Isaiah. Dos conceptos de libertad y otros escritos (Madrid). Alianza editorial, 2005. ISBN: 8420672815.

3. CHILE. TRIBUNAL CONSTITUCIONAL CHILENO. Sentencia rol N³729 (3751)-17 (21, agosto, 2017) [En línea]. [Consultado: marzo 26 de 2020 ] Disponible en: https://www.law.utoronto.ca/utfl file/count/documents/reprohealth/chile-2017sintesis-spanish.pdf

4. COlOMBIA. ASAMBLEA nACIONAL CONSTItUyente. Artículo 18. (04, julio, 1991). Constitución Política de Colombia [en línea]. [Consultado: marzo 12 de 2020]. Disponible en: http://www.secretariasenado.gov.co/senado/basedoc/constitucion politica 1991.h $\underline{\mathrm{tml}}$

5. COLOMBIA. ASAMBLEA NACIONAL CONSTITUYENTE. Gaceta constitucional No 112. (3, julio, 1991) Bogotá D.E. [En línea]. [Consultado: 20 junio de 2020]. Disponible en: http://babel.banrepcultural.org/cdm/ref/collection/p17054coll26/id/3850\#: :text= El\%205\%20de\%20febrero\%20de,Colombia\%20una\%20Asamblea\%20Nacional\%20C onstituyente.\&text=El\%20domingo\%207\%20de\%20julio,4\%20de\%20julio\%20de\%20 $\underline{1991}$ 
Cristian Rojas \& Pedro Contreras. Libertad religiosa y objeción de conciencia institucional en Colombia: Un análisis a partir de la sentencia T-738 de 2015.

6. COLOMBIA. CONSEJO DE ESTADO. Sala de lo Contencioso Administrativo Sección Tercera Sentencia 2013-00257 (13, octubre, 2016). C.P. Guillermo Vargas Ayala [En línea]. [Consultado marzo 12 de 2020] Disponible en: http://legal.legis.com.co/document/Index?obra=jurcol\&document=jurcol 6f5e3e72 4bdb482a993df485e44e354b

7. COLOMBIA. CORTE CONSTITUCIONAL. C.370 de 2019.Expediente: D-12372. (14, agosto, 2019). M.P. Gloria Stella Ortiz [En línea]. [Consultado: marzo 12 de 2020]. Disponible en: https://www.corteconstitucional.gov.co/relatoria/2006/c-355$\underline{06 . h t m}$

8. COLOMBIA. CORTE CONSTITUCIONAL. C-355 DE 2006. Expediente: D- 6122, 6123 y 6124. (10, mayo, 2006). M.P. Jaime Araujo Rentería [En línea]. [Consultado: marzo 12 de 2020]. Disponible en: https://www.corteconstitucional.gov.co/relatoria/2006/c355-06.htm

9. COLOMBIA. CORTE CONSTITUCIONAL. C-539 de 2011. Expediente: D-8351. (6, julio, 2011). Luis Ernesto Vargas Silva. [En línea]. [Consultado: 28 de marzo de 2020]. Disponible en: https://www.corteconstitucional.gov.co/relatoria/2011/C-53911.htm

10. COLOMBIA. CORTE CONSTITUCIONAL. C-728 de 2009. Expediente D-7685. (14, octubre, 2009). M.P. Gabriel Eduardo Mendoza Martelo [En línea]. [Consultado: marzo 20 de 2020]. Disponible en: https://www.corteconstitucional.gov.co/relatoria/2009/C-728-09.htm

11. COLOMBIA. CORTE CONSTITUCIONAL. Expediente T-6.467.142. (26, junio, 2018). M.P. Gloria Stella Ortiz [En línea]. [Consultado: abril 12 de 2020]. Disponible en: https://www.corteconstitucional.gov.co/relatoria/2018/T-238-18.htm

12. COLOMBIA. CORTE CONSTITUCIONAL. SU-096 de 2018. Expediente T-6.612.909. (17, octubre, 2018). M.P. José Fernando Reyes Cuartas [En línea]. [Consultado: marzo 12 de 2020]. Disponible en: https://www.corteconstitucional.gov.co/relatoria/2018/SU096-18.htm 
Cristian Rojas \& Pedro Contreras. Libertad religiosa y objeción de conciencia institucional en Colombia: Un análisis a partir de la sentencia T-738 de 2015.

13. COLOMBIA. CORTE CONSTITUCIONAL. SU-182 de 1998. Expediente T-141334. (6, mayo, 1998). M. P. Carlos Gaviria Díaz [línea]. [Consultado: marzo 16 de 2020]. Disponible en: https://www.corteconstitucional.gov.co/relatoria/1998/SU182$\underline{98 . h t m}$

14. COLOMBIA. CORTE CONSTITUCIONAL. SU-354 de 2017. Expediente T-5.882.857. (25, mayo, 2017). M.P. Iván Escrucería [En línea]. [Consultado: marzo 12 de 2020]. Disponible en: https://www.corteconstitucional.gov.co/relatoria/2017/SU354$\underline{17 . h t m}$

15. COLOMBIA. CORTE CONSTITUCIONAL. T-209 DE 2008. Expediente T-1673450. (28, febrero, 2008). M.P. Clara Inés Vargas [En línea]. [Consultado: marzo 12 de 2020]. Disponible en: https://www.corteconstitucional.gov.co/relatoria/2008/t-209-08.htm 16. COLOMBIA. CORTE CONSTITUCIONAL. T-353 de 2018. Expedientes acumulados T6.367.365 y T-6.372.321. (31, agosto, 2018). M.P. Alberto Rojas Ríos [En línea]. [Consultado: marzo 21 de 2020]. Disponible en: https://www.corteconstitucional.gov.co/relatoria/2018/T-353-18.htm

17. COLOMBIA. CORTE CONSTITUCIONAL. T-388 DE 2009. Expediente T-1.569.183. (28, mayo, 2009). M.P. Humberto Sierra Porto [En línea]. [Consultado: marzo 12 de 2020]. Disponible en: https://www.corteconstitucional.gov.co/relatoria/2009/t-388-09.htm 18. COLOMBIA. CORTE CONSTITUCIONAL. T-406 de 1992. Expediente: T-778. (5, junio, 1992). Ciro Angarita Barón. [En línea]. [Consultado: 28 de marzo de 2020]. Disponible en: https://www.corteconstitucional.gov.co/relatoria/1992/T-406-92.htm

19. COLOMBIA. CORTE CONSTITUCIONAL. T-411 de 1992. Expediente № T-785. (17, junio, 1992). M.P. Alejandro Martínez Caballero [En línea]. [Consultado: marzo 16 de 2020]. Disponible en: https://www.corteconstitucional.gov.co/relatoria/1992/t-41192.htm

20. COLOMBIA. CORTE CONSTITUCIONAL. T-430 de 2013.Expediente: T-3274619 (10, julio, 2013). M.P. María Victoria Calle Correa [En línea]. [Consultado: marzo 12 de 2020]. Disponible en: https://www.corteconstitucional.gov.co/relatoria/2013/T-43013.htm 
Cristian Rojas \& Pedro Contreras. Libertad religiosa y objeción de conciencia institucional en Colombia: Un análisis a partir de la sentencia T-738 de 2015.

21. COLOMBIA. CORTE CONSTITUCIONAL. T-588 de 1998. Expediente T-173807. (20, octubre, 1992). M.P. Eduardo Cifuentes Muñoz [En línea]. [Consultado: abril 12 de 2020]. Disponible en:https://www.corteconstitucional.gov.co/relatoria/1998/t-58898.htm

22. COLOMBIA. CORTE CONSTITUCIONAL. T-738 DE 2015. Expediente T-4.970.823. (30, noviembre, 2015). M.P. Luis Guillermo Guerrero [En línea]. [Consultado: marzo 12 de 2020]. Disponible en: https://www.corteconstitucional.gov.co/relatoria/2015/T-73815.htm

23. COLOMBIA. CORTE CONSTITUCIONAL. C-263 de 2013. Expediente D-93297. (8, mayo, 2013). M.P. Jorge Iván Palacio [En línea]. [Consultado: abril 12 de 2020]. Disponible en: https://www.corteconstitucional.gov.co/RELATORIA/2013/C-263-13.htm

24. COLOMBIA. CORTE CONSTITUCIONAL.C-370 de 2019. Expediente D-12372. (14, agosto, 2019). M.P. Gloria Stella Ortiz [En línea]. [Consultado: abril 12 de 2020]. Disponible en:https://www.corteconstitucional.gov.co/relatoria/2019/C-370-19.htm

25. COLOMBIA. CORTE CONSTITUCIONAL. C-489 de 2002. Expediente D-3838. (26, junio, 2002). M.P. Rodrigo Escobar Gil [En línea]. [Consultado: abril 12 de 2020]. Disponible en: https://www.corteconstitucional.gov.co/relatoria/2002/C-489-02.htm

26. COLOMBIA. CORTE CONSTITUCIONAL. SU-108 de 2016. Expedientes T-2.643.585 y T2.652.480 AC. (03, marzo, 2016). M.P. Alberto Rojas Ríos [En línea]. [Consultado: marzo 21 de 2020]. Disponible en: https://www.corteconstitucional.gov.co/relatoria/2016/SU108-16.htm

27. COLOMBIA. CORTE CONSTITUCIONAL. T-026 de 2005. Expediente T-924708. (20, enero, 2005). M.P. Humberto Sierra Porto [En línea]. [Consultado: abril 10 de 2020]. Disponible en: https://www.corteconstitucional.gov.co/relatoria/2005/T-02605.htm

28. COLOMBIA. SUPERINTENDENCIA DE SALUD. Circular 003 de 2013 (29, abril, 2013). [En línea]. Informe Por la cual se imparten instrucciones sobre la interrupción voluntaria del embarazo (IVE), en aplicación de la Constitución Política de Colombia, los tratados internacionales y las sentencias de la Corte Constitucional, y se deroga la 
Cristian Rojas \& Pedro Contreras. Libertad religiosa y objeción de conciencia institucional en Colombia: Un análisis a partir de la sentencia T-738 de 2015.

Circular número 03 de noviembre de 2011. Diario Oficial No. 48.776 de 29 de abril de 2013. [Consultado: marzo 26 de 2020]. Disponible en: https://docs.supersalud.gov.co/PortalWeb/Juridica/OtraNormativa/C SNS 00032 013.pdf

29. CÓRDOBA, Jhohan. Objeción de conciencia de las personas organizacionales en Colombia. Revista Ciencias Sociales y educación. Medellín, Colombia: Universidad de Medellín, 2018. No 7 (14). p. 39-64. [Consultado: 20 de noviembre de 2020]. DOI:: https://doi.org/10.22395/csye.v7n14a3

30. COSTA RICA, ORGANIZACIÓN DE ESTADOS AMERICANOS. Convención Americana sobre Derechos Humanos. (22, noviembre,1969) [En línea]. [Consultado: abril 10 de 2020]. Disponible en: https://www.oas.org/dil/esp/tratados b32 convencion americana sobre derechos humanos.htm

31. ESTADOS UNIDOS DE AMÉRICA. CONGRESO DE LOS ESTADOS UNIDOS. Bill of rights. (25, septiembre, 1789). [En línea]. [Consultado: marzo 20 de 2020]. Disponible en: https://billofrightsinstitute.org/founding-documents/bill-of-rights/

32. ESTADOS UNIDOS. CORTE SUPREMA DE JUSTICIA. Burwell vs Hobby Lobby. 573 U.S. 682 (30, junio 2011) Autor de la opinión mayoritaria, Samuel Alito [En línea]. [Consultado: marzo 26 de 2020 ] Disponible en: https://www.supremecourt.gov/opinions/13pdf/13-354 olp1.pdf

33. ESTADOS UNIDOS. CORTE SUPREMA DE JUSTICIA.Little Sisters of the Poor $v$. Pensilvania. 591 U.S. (06, julio 2020) Autor de la opinión mayoritaria, Clarence Thomas [En línea]. [Consultado: noviembre 18 de 2020 ] Disponible en: https://www.supremecourt.gov/opinions/19pdf/19-431 5i36.pdf

34. FRANCIA. ASAMBLEA NACIONAL. Declaración de los Derechos del Hombre y del Ciudadano. Artículo 10. (26, agosto,1789) [En línea]. [Consultado: marzo 16 de 2020]. Disponible en: https://www.conseilconstitutionnel.fr/sites/default/files/as/root/bank mm/espagnol/es ddhc.pdf

35. FRANCIA. ASAMBLEA PARLAMENTARIA DEL CONSEJO DE EUROPA. Resolución 1763. (7, octubre, 2010). Informe McCafferty [En línea]. [Consultado: marzo 18 de 2020]. 
Cristian Rojas \& Pedro Contreras. Libertad religiosa y objeción de conciencia institucional en Colombia: Un análisis a partir de la sentencia T-738 de 2015.

Disponible en: $\quad$ https://assembly.coe.int/nw/xml/XRef/Xref-XML2HTMLen.asp?fileid $=17909 \&$ lang=en

36. FRANCIA. Declaración Universal de los Derechos Humanos. Artículo 18. (10, diciembre,1948) [En línea]. [Consultado: marzo 20 de 2020]. Disponible en: https://www.un.org/es/universal-declaration-human-rights/

37. GARCÍA, Leonardo, De la “constitucionalización" a la “convencionalización” del ordenamiento jurídico. La contribución del ius constitutionale commune. Revista Derecho del Estado. Bogotá, Colombia: Universidad Externado de Colombia, 2016. No 36 p.131-166. [Consultado: 20 marzo 2020]. DOI: http://dx.doi.org/10.18601/01229893.n36.05

38. González, Ana. Memorias del Segundo Seminario Regional Latinoamericano, "¿Objeción de conciencia institucional? Impacto en la prestación de servicios de interrupción voluntaria del embarazo”. Bogotá, Colombia, 2017. Consultado el 19 de noviembre de 2020. http://www.codajic.org/sites/www.codajic.org/files/Memorias Seminario Objecion de Conciencia.pdf

39. González, Ana. Objeción de conciencia, bioética y derechos humanos: una perspectiva desde Colombia. Revista Revista Bioética y derecho. Barcelona, España, 2018. No. 42 p. 106-126 (Consultado 16 de noviembre de 2020). http://scielo.isciii.es/scielo.php?pid=S1886-

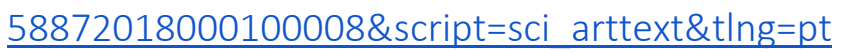

40. ITALIA. CONSEJO DE EUROPA. Convenio para la Protección de los Derechos Humanos y de las Libertades Fundamentales (4, noviembre,1950) [En línea]. [Consultado: abril 10 de 2020]. Disponible en: https://www.echr.coe.int/Documents/Convention SPA.pdf

41. LAYCOCK, Douglas. Religious Liberty for Politically Active Minority Groups: A Response to NeJaime and Siegel. The Yale Law Journal Forum, New Haven, Connecticut: 2016. nro. 125, p. 369-389. [Consultado: 17 marzo 2020]. Disponible en: https://www.yalelawjournal.org/pdf/Laycock PDF wgmv6xbh.pdf 
Cristian Rojas \& Pedro Contreras. Libertad religiosa y objeción de conciencia institucional en Colombia: Un análisis a partir de la sentencia T-738 de 2015.

42. LONDOÑO, María y ACOSTA, Juana, La protección internacional de la objeción de conciencia: análisis comparado entre sistemas de derechos humanos y perspectivas en el sistema interamericano. Anuario Colombiano de Derecho Internacional. Bogotá, Colombia: Universidad del Rosario, 2015. Vol. 9, p. 233-272. [Consultado: 20 marzo 2020]. DOI: $\quad$ http://dx.doi.org/10.12804/acdi9.1.2016.07. Disponible en: https://revistas.urosario.edu.co/index.php/acdi/article/view/4497/3227

43. NADEL, Sean. Closely Held Conscience: Corporate Personhood in the Post-Hobby Lobby World. Columbia Journal of Law, Nueva York: 2016. Vol. 50, p.417 448. [Consultado: 12 febrero 2020]. Disponible en: http://jlsp.law.columbia.edu/wpcontent/uploads/sites/8/2017/05/50-Nadel.pdf

44. NEJAIME, Douglas y SIEGEL, Reva. Conscience Wars: Complicity-based Conscience Claims in religion and politics. En: The Yale Law Journal. New Haven, Connecticut: 2014. Vol. 124, nro. 7, p. 2516-2591. [Consultado: 17 marzo 2020]. Disponible en: https://www.yalelawjournal.org/feature/complicity-based-conscience-claims

45. NÚÑEZ, Alexander y CABELLO, Javiera. Objeción de conciencia institucional y regulación en salud: ¿existe una excusa legítima frente al aborto en Chile? Revista de Bioética y Derecho Barcelona: 2018. No 43, p.162-177. [Consultado: 12 mayo 2020]. DOI: https://doi.org/10.1344/rbd2019.0.204122

46. PARDO, Cristina. La objeción de conciencia en la jurisprudencia de la corte constitucional colombiana. Revista Persona y Bioética. En: Bogotá Colombia: 2006. Vol. 10, nro. 1, p. 52-68. [Consultado: 17 marzo 2020]. Disponible en: https://personaybioetica.unisabana.edu.co/index.php/personaybioetica/article/vie $\underline{w / 928 / 1008}$

47. PRIETO, Vicente.La objeción de conciencia en instituciones de salud. (Colombia).Editorial Temis SA y Universidad de La Sabana, 2013. ISBN: 2655 201300026500.

48. PRIETO, Vicente. Dimensiones individuales e institucionales de la objeción de conciencia al aborto. Revista general de derecho canónico y derecho eclesiastico del 
Cristian Rojas \& Pedro Contreras. Libertad religiosa y objeción de conciencia institucional en Colombia: Un análisis a partir de la sentencia T-738 de 2015.

Estado. En: Bogotá Colombia: 2012. Vol. 30. [Consultado: 20 noviembre 2020]. Disponible en: https://dialnet.unirioja.es/servlet/articulo?codigo=4067418

49. SEPPER, Elizabeth. Free Exercise Lochnerism. Columbia Law Review Nueva York, Nueva York: 2015. Vol. 115, p.1453-1519. [Consultado: 12 febrero 2020]. Disponible en: https://columbialawreview.org/wp-content/uploads/2016/02/October-2015-7Sepper UPDATE.pdf

50. TUSHNET, Mark. Do for-profit corporations have rights of religious conscience?. En: Cornell law review. Ithaca, Nueva York: 2013. Vol. 70, nro. 71, p. 70-85. [Consultado: 17 marzo 2020].

Disponible en: https://heinonline.org/HOL/LandingPage?handle=hein.journals/clro2\&div=6\&id=\&p $\underline{\text { age }=}$ 